\title{
COMPARING POLLINATION BAG TYPES FOR MICRO-ENVIRONMENTAL PARAMETERS INFLUENCING SEED PRODUCTION IN OIL PALM
}

\section{LUC BONNEAU*; DEBORAH ELI*; PHILLIP VOVOLA* and DALJIT SINGH VIRK**}

\begin{abstract}
For oil palm seed production, the pollination bag must prevent contamination by unintended pollen to ensure the genetic integrity. An investigation was undertaken by the seed production unit of Dami Oil Palm Research Station (DAMI OPRS) in Papua New Guinea to compare the impact of the type of pollination bags on both the genetic integrity and seed yield in the commercial seed production environment. Three pollination bag types [canvas, high density polyethylene (HDPE) and polyester] were compared during pollination and blank pollination exercises.

The production of seeds and results for intactness, presence of insects, impact of water and economic parameters such as average time taken for isolating, demonstrated that the polyester bags outperformed the HDPE and canvas bags.

Bunches isolated with polyester bags produced 13\% more seeds per bag than the HDPE bags and 6\% more seeds per bag than those using canvas. The canvas bag took longer to apply than the polyester or HDPE bags, and was not averting presence of insects. Both HDPE and canvas bags showed significant collapse when wet. The resulting economics on seed production profitability and risk of contaminations which would alter commercial reputation indicate that the polyester bags are a better choice than the canvas and HDPE bags.
\end{abstract}

Keywords: oil palm seed, pollination bag, canvas, HDPE, polyester.

Date received: 21 September 2015; Sent for revision: 10 October 2015; Received in final form: 30 December 2016; Accepted: 5 January 2017.

\section{INTRODUCTION}

Corley and Tinker (2008) have described the oil palm physiology and architecture. Oil palms are monoecious with separate male and female inflorescences in leaf axils but as a single inflorescence per leaf on the same plant. Anthesis on both types of inflorescences lasts for about three days which is usually not sufficient time for two subsequent inflorescences on the same palm to pollinate one another.

* Dami Oil Palm Research Station, P.O. Box 165 Kimbe, West New Britain Province, Papua New Guinea.

E-mail: Ibonneau@nbpol.com.pg

** School of Environment, Natural Resources and Geography (SENRGy), Bangor University, Bangor, Gwynedd, Wales LL57 2UW, United Kingdom.
In the wild, the oil palm is naturally pollinated by wind but predominantly by insect pollinators, the most specific of which is the weevil Elaeidobius kamerunicus Faust (Coleoptera: Curculionidae) while other insects are as marginal pollinators as wind itself (Basri and Norman, 2007). The introduction of this weevil revolutionised the oil palm industry in the early 1980s in South-east Asia which increased the fresh fruit bunch (FFB) production by $30 \%$ per unit of area in the first year after its introduction in Malaysia (Basri et al., 1983). In Papua New Guinea, the assisted pollination was stopped in all oil palm basins only three to four months after the introduction of the weevils (Menendez and Prior, 1982). As such in a commercial oil palm stand, the weevil population reaches tens of thousands of individuals per hectare being attracted by the scent of anthesing male or female inflorescences. 
Plant breeders and seed producers are interested to produce seeds of known pedigree which requires the hybridisation between only the chosen male and female parental inflorescences. To achieve this, the use of isolation bags in breeding of many types of plant species from grain crops to trees is widespread (Harries, 1972; Bridgwater et al., 1998; Windham and Williams, 2007). To ensure the genetic integrity of seed produced, the pollen harvested and later used in pollination has to be of known origin and that the female inflorescences need to be isolated with a bag to exclude contamination from unknown pollen and to create controlled environment for seed development following pollination within the bag. The success and quality of hybrid seed production depends upon the effectiveness of pollination bags (Smith and Mehlenbacher, 1994) in respect of maintaining genetic integrity of crosses by forbidding the access of foreign pollen carried by wind or insects. An equally important aspect is for the bag to allow good development of bunches which are characterised by a high fruit set from the assisted pollinated bunches and the resulting numerous seeds. In oil palm, hybrid seed production pollination bags must withstand damage from the plant's tough abrasive physiology; as well as the climatic vagaries including ultra violet light, rain and wind; and also create the most conducive micro-environmental conditions for seed production within the bag. Unconducive growth conditions inside the bag such as dampness may increase the probability of disease incidence on the developing seeds (Windham and Williams, 2007). Therefore, breeders and seed producers of various plant species have been long seeking the best pollination bags which can be made from a range of materials each of which has its shortcomings (Smith and Mehlenbacher, 1994). The different options may be very different in fabric, cost or ease of use.

However, very few studies on systematic controlled comparisons of different types of pollination bags have been made, e.g. Smith and Mehlenbacher (1994) and Windham and Williams (2007). Our review of literature shows that this is the first investigation of the kind in oil palm that is intended to evaluate different pollination bags for some parameters influencing within bag microenvironment conditions and to compare their efficiency for economic yield and perform a bioeconomic analysis for seed production in oil palm.

The present study undertaken at the Dami Oil Palm Research Station (Dami OPRS) in West New Britain, Papua New Guinea compares three pollination bag types [based on 1) canvas, 2) a non-woven high density polyethylene (HDPE) and 3) a non-woven polyester materials] during commercial seed production of oil palm (Elaeis guineensis Jacq.).

\section{MATERIALS AND METHODS}

The present study compared the following three type of bags which are made of: canvas, HDPE and polyester materials.

\section{Canvas}

Canvas is an extremely durable plain-woven fabric made from either linen, cotton or sometimes hemp. Typically, it is used for making sails, marquees, bags, canvasses for painting and shoes. It is strong and sturdy and can be easily cut and sewn into the required shape. These bags have the advantage of being cheap and are often reused, however the natural cellulose in the fibres attracts insects (Hodges, 2003) and the plain woven design can give a straight through hole that pollen and weevils can penetrate; stitching enhances this.

\section{HDPE}

HDPE is lightweight and durable material widely used for purposes such as graphic display, for construction and packaging. Stronger than paper and more cost-effective and versatile than fabrics, and has a higher strength-to-weight ratio than paper, absorbs little or no moisture, is strong and rip-resistant. It is the most widely used polymer for manufacturing in plastic carrier bags through to large-scale water pipes (CIEC_Promoting_Science, 2015).

\section{Polyester}

Polyester is tougher than paper and very flexible. Designed with the goal of allowing the internal micro-climate to be as similar as possible to the external environment, polyester is also highly breathable and allows water vapour to pass through readily while absorbing only a minimal amount of water. Polyester is also sometimes known as polyethylene terephthalate (PET). Polyesters are polymers formed from a dicarboxylic acid and a diol. They exist in many forms and can be used for moulding composites, water bottles, fibres for clothing, etc. The architecture of the fibres leads to a torturous route that restricts pollen getting through.

The three bags types were evaluated for two important properties; efffectiveness of creating ambient micro-environment free of insects within the bag and the total seed yield. Given in Figure 1 are the picture of the bags and in Table 1 is provided a brief assessment of visual characteristics.

\section{Creating and Assessing a Suitable Micro- environment}

The observations on micro-environmental parameters were collected over the 31 days period 
during which operators used the bags for female inflorescence isolation. Three key measures were used to evaluate this property of the bags by taking daily pictures of intactness of the bag, inspection of insect contamination and removal of water. If water was found, it was removed with a $10-\mathrm{ml}$ syringe. Once the water was collected the hole made by the needle on the bag was resealed using tape to avoid insect entry. The scoring parameters and scoring methods are presented in Table 2.

\section{Evaluating Bag Types for Economic Parameters}

Time in minutes was recorded for bagging every inflorescence by workers over the 31-day period. Once the seed bunch had matured, normal harvesting and seed production processes were undertaken.

The number of resulting seeds per bunch/ bag was counted as indicative of seed yield. As a further check on the robustness of the findings, we computed two types of analyses of seed yield. The first on the total seed produced and the second on the average number of seeds per bunch. The percentage of all the seeds produced in the study coming from each bag type was computed by using the total seed count per bag divided by the overall total seed number from all bags and multiplied by 100 .

Three assumptions are made to estimate the potential impact of seed yields on revenue. An average resale price of USD 1 per seed is assumed.

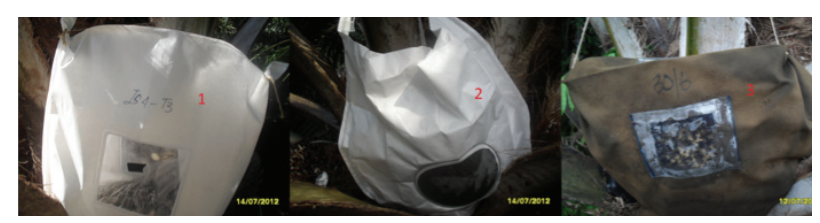

Figure 1. The three different types of bags used in the comparative study 1: polyester, 2: high density polyethylene (HDPE), 3: canvas.

TABLE 1. BASIC CHARACTERISTICS OF THE ISOLATION BAGS TYPES

\begin{tabular}{ll}
\hline Bag type & Characteristics \\
\hline Polyester & Smooth paper like texture \\
& Two windows \\
& Light weight and breathable \\
& Smooth, slippery texture \\
HDPE & Fasteners attached \\
& One window \\
& Light weight \\
& Rough texture \\
Canvas & Little sunlight penetration \\
& Inexpensive \\
& Two windows \\
\hline
\end{tabular}

Note: HDPE - high density polyethylene.
TABLE 2. SCORING THE POLLINATION BAG FOR MICRO-ENVIRONMENT

\begin{tabular}{cccc}
\hline & \multicolumn{3}{c}{ Parameter } \\
\cline { 2 - 4 } Score & Intactness of bag & Insect count & Water test \\
\hline 1 & Collapse & Present & Dry \\
2 & Shrunk & Absent & Moist \\
3 & Intact & - & Wet + water \\
\hline
\end{tabular}

A flat $75 \%$ germination rate is also assumed, since pollination bag type may not be a determinant of germination rate several months later, and only germinated seeds are typically sold. Finally, it is assumed that all produced and germinated seeds are sold.

The cost of the isolation bags was also taken in consideration.

\section{Inflorescence Isolation Method and the Design of Experiment}

The inflorescence of both sexes is a compound spadix with often over 100 spikelets, initially enclosed in a spathe or bract that splits two weeks prior to anthesis (Corley and Tinker, 2008). Operators carrying out the isolations have to remove all sources of contamination before the opening of the spathes. Soon after the identification of the male or female inflorescence, the operator will clear the area surrounding the inflorescence on the palm, eradicate all insects from that surrounding by the use of sprayed insecticide, remove the spathes, and finally promptly bag the young immature inflorescence to create a controlled environment.

In the case of female inflorescence which will mature into a seed bunch, operators will manually puff pollen of known origin in two consecutive occasions during the three-day anthesing period through a small sealable dedicated opening made in the isolation bag.

The available plantation of mother plants used for Dami PNG seed production was used in an appropriate manner to design the experiment. The palms varied in age and location in the seed garden. Perhaps, more appropriately, age of palm could have been used as blocks in the experiment but it was not possible due to the available number of palms in any age group to be allocated to all treatments. We allowed for the effect of age of palms on number of seeds per bunch in various ways. Firstly, we selected only mature seed garden between 12 and 16 years of age at the time of the experiment. Secondly, we allowed for the age effect of palms in the layout of the experiment. Four plantation workers fitted the bags for the study, each being asked to fit 20 bags of each type to a total of 240 randomly selected mother palms. Furthermore, in order to minimise the age effect, 20 palms of the same age were used for a bag 
(Table 3).Thirdly, the effect of age was assessed by a covariance analysis (see analysis). In the twofactor (bag types and workers) experimental design 20 random trees allocated to an age group were treated as replicates within the main factors.

The standard isolation procedure, used by Dami OPRS was carried out in this experiment. The field was surveyed on a daily basis to select female inflorescences before anthesis stage.

In the standard procedure, the selected palms are marked and the female inflorescences bagged 7-10 days before they became receptive. This involves cleaning to remove spathes and clearing the base for ease of applying the pollination bag. The exposed inflorescence is then sprayed with a $40 \%$ formalin solution to kill any foreign pollen and sprayed with broad spectrum insecticides (Esbiothrin, Permethrin, N-Octyl Bicyclophene dicarboximide) contained in pressurised dispenser of Mortein ${ }^{\circledR}$. The inflorescence is then isolated using a pollination bag, which is wedged in place using a chisel and tied for extra assurance that no foreign pollen can enter via the base. As a further security measure, two cotton wool rolls with Carbofuran - a strong carbamate insecticide found in Furadan ${ }^{\circledR}$, is placed at the base to deter insects. The Carbofuran strong scent will deter insects entering the bag for a sufficient period of three to four weeks.

The design and material allow ease in operation and handling of bag during applying it over the inflorescence. All four workers noted the start and finish time of putting the bag on each palm and calculated the total time taken in minutes.

Once isolated in this way, the bags were kept on the female inflorescence until the flowers were receptive. At this stage, pollen was puffed into the bag and the resulting hole covered with tape. The bag stayed in place for a further 31 days after pollination, after which it was removed and the fruit allowed maturing normally.

All three bag types are being used by oil palm breeders for sometimes and are well tested for their no contamination and hence, the emphasis on blank pollination was reduced in the present study. The average pollen size of E. guineensis ranges from 31 to $32 \mu \mathrm{m}$ with triangular shape and rounded angles (Ibrahim et al., 2012). The average pore size of polyester materials is about $10-15 \mu \mathrm{m}$ as compared to $<1 \mu \mathrm{m}$ of HDPE bags.

Data on blank pollinations and contaminations are given in Table 4. On all blank pollinations performed with polyester no contamination was recorded. For blank pollinations, the operators are not made aware that they are provided with ampoules of pure talcum powder, in order to make sure that operators are not over-cautious for the operation but work upon the company standard operating procedures.

\section{Statistical Analysis}

All bag traits such as intactness, water score and time taken to tying were analysed by the analysis of variance approach following Snedecor and Cochran (1974). Palm age in years was used as a covariate in the analysis of variance for seed count to assess the significance of regression of seed count on age of palm. The sum of squares for bag types was partitioned into orthogonal comparison of HDPE vs. canvas and polyester vs. others for 1 degrees of fredom (df) each. The pooled error was derived from between palms within bag types and workers for $197 \mathrm{df}$ because of 31 missing values for different reasons. Estimation of error variance within each age block of 20 palms eliminates the effect of age and worker from the error variance. A simple t-test was also used for testing the significance of difference between the mean seed count of different bag types.

\section{RESULTS}

\section{Evaluating Bag Types for Micro-environmental Differences}

Intactness of bags. The three types of bags showed significant differences for intactness (Table 5).

However, differences between workers were also significant; worker 1 recorded the highest mean intactness score of 2.43 compared with the lowest score of 1.91 by worker 3 . The ranking of the bags showed differences between workers. Thus, the bag type $\mathrm{x}$ worker interaction was significant.

Despite this interaction, differences between bag types for mean intactness were large. The canvas bags performed the lowest, being prone to

TABLE 3. AGE IN YEARS (from planting time) OF 20 PALMS USED AS A GROUP FOR A BAG TYPE BY ANY OF FOUR WORKERS

\begin{tabular}{lllll}
\hline Bag type & Worker $\mathbf{1}$ & \multicolumn{1}{c}{ Worker 2 } & \multicolumn{1}{c}{ Worker 3 } & \multicolumn{1}{l}{ Worker $\mathbf{4}$} \\
\hline Polyester & 14.7 (May 1998) & 11.7 (May 2011) & 13.4 (August 1999) & 16.3 (September 1996) \\
HDPE & 11.7 (May 2001) & 11.7 (May 2011) & 14.7 (May 1998) & 13.4 (August 1999) \\
Canvas & 14.7 (May 1998) & 14.0 (December 1998) & 14.0 (December 1998) & 14.7 (May 1998) \\
\hline
\end{tabular}

Note: HDPE - high density polyethylene. 
TABLE 4. SUMMARY OF BLANK POLLINATIONS AND CONTAMINATIONS

\begin{tabular}{|c|c|c|c|c|c|}
\hline Bag type & $\begin{array}{c}\text { Worker } \\
\text { (W) }\end{array}$ & $\begin{array}{c}\mathrm{N} \\
\text { (trees) }\end{array}$ & Pollinated $=1$ & Blank pollination $=0$ & $\begin{array}{l}\text { Contamination } \\
\text { No }=0 ; \text { Yes }=1\end{array}$ \\
\hline Canvas & W4 & 20 & $\begin{array}{l}3 \text { with past age } \\
16 \text { with score }=1\end{array}$ & 1 Blank poll & Yes \\
\hline HDPE & W4 & 20 & 19 with score $=1$ & 1 with score $=0$ & Yes \\
\hline Polyester & W4 & 20 & 20 with score $=1$ & None for blank poll. & No \\
\hline Canvas & W3 & 20 & $\begin{array}{l}18 \text { with score }=1 \\
2 \text { with past age }\end{array}$ & None for blank poll. & No \\
\hline HDPE & W3 & 20 & 19 with score $=1$ & 1 with score $=0$ & No \\
\hline Polyester & W3 & 20 & 20 with score $=1$ & None for blank poll & No \\
\hline Canvas & W2 & 20 & 18 with score $=1$ & 2 with score $=0$ & No \\
\hline HDPE & W2 & 20 & 20 with score $=1$ & None for blank poll & No \\
\hline Polyester & W2 & 20 & $\begin{array}{l}19 \text { with score }=1 \\
1 \text { abnormal }\end{array}$ & None for blank poll & No \\
\hline Canvas & W1 & 20 & 19 with score $=1$ & 1 with score $=0$ & Yes \\
\hline HDPE & W1 & 20 & 20 with score $=1$ & None for blank poll & No \\
\hline Polyester & W1 & 20 & 20 with score $=1$ & None for blank poll & No \\
\hline
\end{tabular}

Note: HDPE - high density polyethylene.

total 'collapse' as the material absorbed water and gained weight. The HDPE bag performed poorly, losing shape and appearing to 'shrink' and was not significantly different from the canvas bag. By contrast, the polyester bags were significantly different to the other two bag types (Table 6). They kept their shape intact without shrinking onto the inflorescence, resulting in minimal contact of the bag with the inflorescence, and hence, helped in creating a good micro-climate within them for healthy seed set and development.

Water score. The three types of bags differed significantly for water score, the mean water retention score of HDPE bag was significantly lower than canvas or polyester bags (Table 6). However, the canvas and polyester bags did not show a significant difference for water retention despite some of the canvas bags being observed to absorb water into the fabric.

The $6.25 \%$ of HDPE bags (5 out of 80 bags) used for the experiment had accumulated water ranging from 0.11 litres to 12 litres per bag, and averaging 4 litres per bag extracted over the course of the 31 days. The researchers speculate that this might be due to holes created during the isolation process, believing it is unlikely to arise from result of inflorescence transpiration, because water was present in a few bags and only after rain.

Canvas proved partially effective, with some moisture on the bag, primarily on the lower part of the bags after rain. The polyester bags performed well with no water found inside the bags or accumulating on the material.

Presence of insects. The HDPE and polyester bags performed well, with no observed insect contamination in all 80 bags per type fitted by the four workers. On the other hand, although made from strong woven material, 4 out of 80 of the canvas bags were found to have been contaminated by weevils, probably gaining access through the side stitches. The occurrence of insects in canvas bags was recorded by three of out four workers. Worker 1 recorded 30 weevils on one bunch, worker 3 recorded more than 100 weevils on one bunch and worker 4 recorded presence of 20, >100 and 5 weevils on three distinct bunches respectively.

Time factor. The analysis of variance for time taken for bagging showed significant differences between bag types and workers (Table 7). The ranking of time taken for bagging with a type of bag was not consistent over workers leading to a significant worker $\mathrm{x}$ time interaction.

Nonetheless, the average time taken for bagging an inflorescence with canvas bag was $3.26 \mathrm{~min}$ which was significantly more than the other two types of bags (Table 8 ).

TABLE 5. ANALYSIS OF VARIANCE FOR DIFFERENT PARAMETERS RELATED TO MICRO-ENVIRONMENT WITHIN BAGS

\begin{tabular}{lrlrl}
\hline Source & df & Intactness & df & Water score \\
\hline Bag type & 2 & $6.90^{* * *}$ & 2 & $0.38^{*}$ \\
Worker & 3 & $2.59^{* * *}$ & 3 & $0.08 \mathrm{~ns}$ \\
Bag type x worker & 6 & $9.15^{* * *}$ & 6 & $0.12 \mathrm{~ns}$ \\
Error & 215 & 0.18 & 226 & 0.08 \\
\hline Total & 226 & - & 237 & - \\
\hline
\end{tabular}

Note: df - degrees of freedom.

$*$, **, *** Significant at 5\%,1\% and $0.01 \%$ probability level, respectively. ns - non-significant. 
TABLE 6. MEAN VALUES AND STANDARD ERRORS (SE) FOR USABILITY TRAITS OF BAGS

\begin{tabular}{|c|c|c|}
\hline \multirow[t]{2}{*}{ Bag type } & $\begin{array}{l}\text { Intactness }(1=\text { collapse, } \\
2=\text { shrinking, } 3=\text { intact })\end{array}$ & $\begin{array}{l}\text { Water score }(1=\text { no } \text { water, } \\
2=\text { moisture, } 3=\text { water present }\end{array}$ \\
\hline & Mean \pm SE & Mean \pm SE \\
\hline Canvas & $1.98 \pm 0.05$ & $1.01 \pm 0.03$ \\
\hline HDPE & $2.06 \pm 0.05$ & $1.13 \pm 0.03^{* *}$ (both) \\
\hline Polyester & $2.54 \pm 0.05^{* *}$ (both) & $1.00 \pm 0.03$ \\
\hline
\end{tabular}

Note: ** Significantly different from the other two types at $1 \%$ level of probability.

HDPE - high density polyethylene.

Seed count. Of the 80 bags of each type used, not all yielded bunches suitable for seed count analysis. For instance, some were used in blank pollination tests, some bunches were observed to abort during development phase and some (especially the canvas) were affected by site specific social behaviour, with some villagers removing them for personal use.

The number of bagged bunches harvested from HDPE bags was 73, from polyester bags it was 70, and from canvas it was 66 .

The number of seeds per bunch was computed after discards arising from processing, fungus and abnormal seeds identified during normal seed grading. The number of seeds per bunch to successfully mature, across all bag types, varied substantially from as few as 40 seeds per bunch to as many as 2180 per bunch. The total number of seeds from each type of bag varied from 68179 to 77695 .

The analysis of variance showed nonsignificant effect of age of palm on seed count which means that no allowance needs to be made for the regression of seed count on palm age (Table 9). Both bag types and workers showed significant differences along with their interaction. The orhtogonal contrasts of partitioning of bag types sum of squares into HDPE vs. canvas and polyester vs. others showed both of them to be significant which means that HDPE seed count was significantly higher than that of canvas bags and that polyester bags yielded more than other two bag types (Table 9).

The interactions of bag types with workers for seed count were highly significant (Table 9).

TABLE 7. ANALYSIS OF VARIANCE FOR TIME TAKEN (min) IN APPLYING BAGS

\begin{tabular}{lrc}
\hline Source & df & $\begin{array}{l}\text { Time taken (min) } \\
\text { mean squares }\end{array}$ \\
\hline Bag type & 2 & $3.34^{* *}$ \\
Worker & 3 & $20.14^{* * *}$ \\
Bag type x worker & 6 & $20.42^{* * *}$ \\
Error & 215 & 0.51 \\
\hline Total & 226 & - \\
\hline
\end{tabular}

Note: ${ }^{* *}{ }^{* * *}$ Significant at $1 \%$ and $0.01 \%$ probability level, respectively. df - degrees of freedom.
Despite significant interaction the main effects of workers and bag types were also highly significant. Clearly, worker and bag type can produce variable results of seed set following pollination in oil palm. Researchers need to choose both workers and bag types very carefully. Details of interactions are given in Table 10 and Figure 2.

The interactions arise when the ranking of bag types is not consistent over workers. For example, on average, polyester is ranked 1 but it is not ranked 1 by all workers being ranked 1 by workers 3 and 4 but ranked 3 by workers 1 and 2 . Thus, the rank of polyester is not consistent over all workers and the choice of worker can influence the evaluation score. On average, canvas bag is ranked 2 but individual workers differed in its ranking as worker 2 ranked it as 1 and workers 1 and 3 ranked it as 2, and worker 4 ranked it 3. HDPE bag was ranked 3 on average but it was ranked 3 only by worker 3 while worker 1 ranked it 1 and workers 2 and 4 ranked it as 2 . The interactions of workers $x$ bag type are very strong as they are spread over all workers and bag types without a specific trend. The polyester with highest value by worker 4 significantly differs from canvas and polyester by worker 1; HDPE and polyester by worker 2; HDPE by worker 3 and canvas by worker 4. This has implications in choosing appropriate worker for use of pollination bags in oil palm. As far as possible, the effect of changing the worker be minimised by employing equally well experienced workers during pollinations in oil palm. All workers should use the same amount of pollen as differential pollen amount leads to differential seed set (Harun

TABLE 8. MEAN VALUES AND STANDARD ERRORS (SE) FOR TIME TAKEN IN APPLYING THE BAGS

\begin{tabular}{ll}
\hline Bag type & $\begin{array}{l}\text { Time taken (min) } \\
\text { Mean } \pm \text { SE }\end{array}$ \\
\hline Canvas & $3.26 \pm 0.08^{* *}$ (both) \\
HDPE & $2.89 \pm 0.08$ \\
Polyester & $2.88 \pm 0.08$ \\
\hline
\end{tabular}

Note: ${ }^{* *}$ Significantly different from the other two types at $1 \%$ level of probability.

HDPE - high density polyethylene. 
TABLE 9. ANALYSIS OF VARIANCE FOR TOTAL SEED COUNT PER BUNCH (bag)

\begin{tabular}{lrrl}
\hline Source & df & \multicolumn{1}{c}{ MS } & F \\
\hline Palm age (years) & 1 & 328217 & $2.00 \mathrm{~ns}$ \\
Between bag types & 2 & 4980479 & $30.29^{* *}$ \\
HDPE vs. canvas & 1 & 1399923 & $8.51^{* *}$ \\
Polyester vs. others & 1 & 3580556 & $21.78^{* *}$ \\
Between workers & 3 & 11902861 & $72.39^{* *}$ \\
Bag types x workers & 6 & 10231771 & $62.23^{* *}$ \\
Pooled within error $\xi$ & 197 & 164422 & - \\
\hline
\end{tabular}

Note: ns - not significant. ${ }^{* *}$ Significant at $1 \%$ level. $\xi$ - pooled error variance is between trees/bag types/workers -

$\Sigma_{i, 1}^{b} \Sigma_{i, t-1)}^{w}$ where $b$ - bag types (3) and $w$ - workers (4) and $t$ - trees $(20)=3 \times 4 \times 19-31$ missing values $=197$.

HDPE - high density polyethylene. number of seeds obtained per bag showed a wide variation; the highest number of 1098 seeds from polyester bags and the lowest of 969 from HDPE bags (Table 10).

The polyester bag significantly yielded higher average number of seeds per bag than both canvas and HDPE bags, while canvas bags yielded significantly higher than the HDPE bags (Table 11).

The polyester bags showed a $13 \%$ increase in average seed set over the HDPE bags and $6 \%$ over the canvas bags, and canvas bags showed a $7 \%$ increase over the HDPE bags (Table 12).

\section{Impact on Revenue and Cost}

In Table 12, the seed count shows a polyester bag yields $129(13 \%)$ more seeds, on average, than the

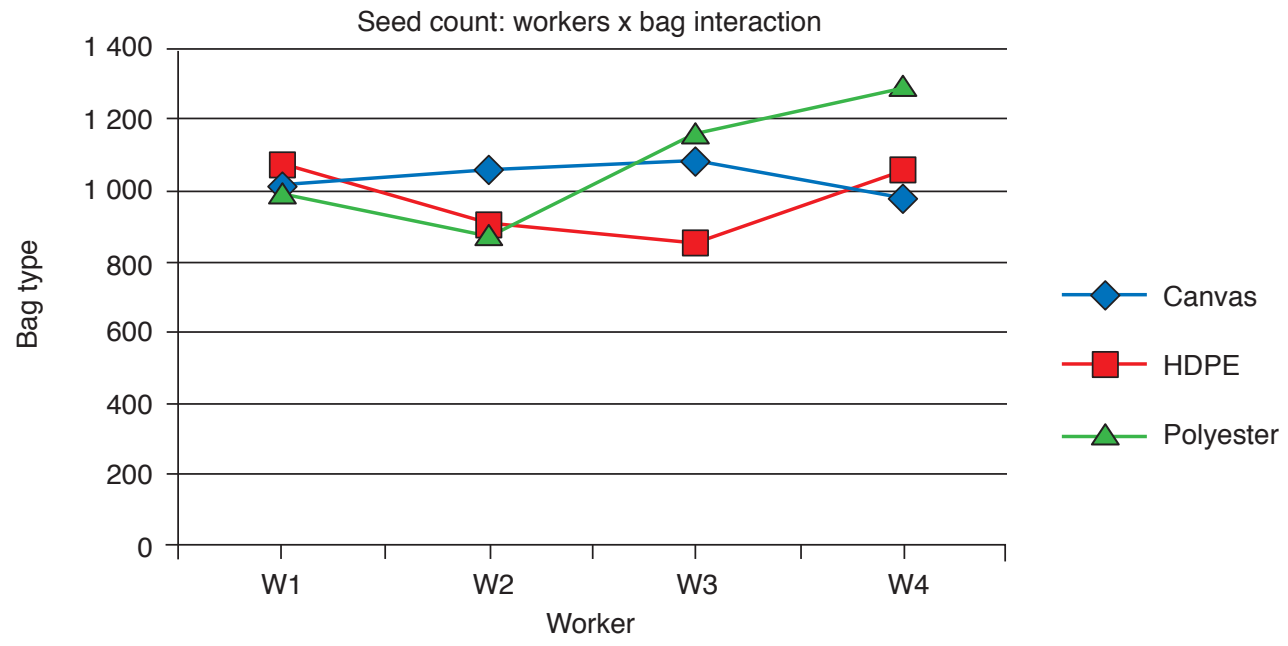

Note: HDPE - high density polyethylene.

Figure 2. Plot of seed count for bag types against workers.

TABLE 10. MEAN SEED COUNT PER BAG TYPES (B), WORKERS (W) AND THEIR INTERACTIONS

\begin{tabular}{lrrrrrr}
\hline Bag type & W1 & W2 & W3 & W4 & Mean (B) & SE mean \\
\hline Canvas & 1007 & 1055 & 1087 & 981 & 1033 & 6.1 \\
HDPE & 1071 & 902 & 854 & 1055 & 969 & 5.6 \\
Polyester & 994 & 885 & 1169 & 1300 & 1098 & 5.8 \\
Mean (W) & 1023 & 946 & 1030 & 1123 & 1033 & - \\
SE mean & 7.7 & 8.1 & 8.0 & 7.4 & - & - \\
SE diff. interaction & 128.2 & - & - & - & - & - \\
LSD 5\% interaction & 251.3 & - & - & - & - & - \\
\hline
\end{tabular}

Note: LSD - Least significant difference. SE - Standard Error. HDPE - high density polyethylene.

and Noor, 2002). Allocating all bag types equally to each worker, as done in this study, is appropriate otherwise worker effect will be confounded with bag type if one worker is allocated only one type of pollination bag.

Of the 215824 seeds produced in the study, $32 \%$ came from the canvas bags, 33\% from HDPE bags and $36 \%$ from the polyester bags. The average
HDPE bag and $65(6 \%)$ more seeds than the canvas bag. Canvas bag yields $64(7 \%)$ more seeds than the HDPE bag which equates to USD 96.53, USD 48.88 and USD 47.65 extra revenue, respectively.

On the scale of a commercial seed production unit (e.g., 1 million seeds or greater), this could be expected to be a linear relationship that could rapidly have a large impact on the overall economics 
(Figure 3). Over a quantity of 1000 bags the advantage of the polyester bags translates into as much as USD 96530 extra revenue compared to HDPE bags. The additional benefit from the polyester bags over the canvas bags for 1000 bags turns out to be USD 48 878. The canvas bags give additional revenue of USD 47652 over the HDPE bags.

The data suggest (Table 12) that to produce 1 million germinated seeds using polyester bags reduces the number of bunches required by 161 compared to HDPE bags and 77 compared to canvas bags. Use of canvas bags reduces the number of bunches by 85 compared to HDPE.

\section{DISCUSSION}

All crossing programmes and hybrid seed production procedures generally depend upon creating an effective barrier between reproductive parts of flowers and environment. Paper is the simplest and oldest material used for making pollination bags but over time more suitable materials have been developed and used by plant breeders, e.g., made from muslin, micro-mesh, polyethylene, cellulose acetate, micro-pore acetate bread bags (Pickering, 1982; Ball et al., 1992; Wyatt et al., 1992; McGranahan et al., 1994; de Rio and Caballero, 1999; Neal and Anderson, 2004). Paper materials though used by plant breeders of crop plants, are generally not considered useful for oil palm hybrid seed production. Apparently, comparison of new materials from both woven and non-woven fabrics is highly desirable for oil palm seed production. While no such research is available in oil palm, we shall draw some parallels from other plant species, e.g. McAdam et al. (1987) compared three grades of polyester for pollen proofing in Lolium perenne and Vogel et al. (2014) obtained four- to 10-fold increase in seed produced per cross in micro-mesh fabric pollination bags in switchgrass that allowed larger progeny for evaluation in replicated trials. In olive pollination studies, del Río and Caballero (1999) found that micro-pore paper bags were better than normally used silky or glossy or brown matt paper for checking the contamination from foreign pollen. They also reported that the double bag of micro-pore paper allows for good fruit set and fruit development. In Pinus patula, $\mathrm{Nel}$ et al. (2003) compared micro-fibre isolation material with polyethylene type for cone development and found that seed yields improved with micro-fibre materials than polyethylene material because relative humidity $(\mathrm{RH})$ inside the micro-fibre bags was lower during daytime hours compared with the polyethylene and sponge treatments. They reported that the type of isolation material used during controlled pollination has a major impact on cone survival and seed set.

Further, the perfection of bagging method in controlling outcrossing is also important to

TABLE 11. SEED NUMBER AND BUNCH NUMBER STATISTICS AND COMPARISON OF MEAN VALUES OF BAGS

\begin{tabular}{lccccc}
\hline Bag type & $\begin{array}{c}\text { No. of bagged } \\
\text { bunches in seed } \\
\text { count analysis }\end{array}$ & $\begin{array}{c}\text { Total number of } \\
\text { seeds }\end{array}$ & $\begin{array}{c}\% \text { of total seeds } \\
\text { by bag type }\end{array}$ & $\begin{array}{c}\text { Aver. seed } \\
\text { number /bag }\end{array}$ & $\begin{array}{c}\text { Based on } \\
\text { average seeds } \\
/ \text { bag, } \% \\
\text { generated by } \\
\text { each bag type }\end{array}$ \\
\hline Canvas & 66 & 68179 & 31.6 & $1033 \pm 6.1^{* *}(2)$ & 33.3 \\
HDPE & 73 & 70772 & 32.8 & $969 \pm 5.6^{* *}(1)$ & 31.3 \\
Polyester & 70 & 76873 & 35.6 & $1098 \pm 5.8^{* *}(1,2)$ & 35.4 \\
Total & 209 & 215824 & 100.0 & 3100.6 & 100.0 \\
\hline
\end{tabular}

Note: ** Significant at $1 \%$ level of probability. Numbers in brackets correspond to the bag names given in column 1 in that order and indicate bag types from which the mean is significantly different. HDPE - high density polyethylene.

TABLE 12. MODELLING OF ECONOMIC IMPACT OF BAG TYPE ON POTENTIAL REVENUE AND COST

\begin{tabular}{|c|c|c|c|c|}
\hline Comparison & $\begin{array}{l}\text { Incremental seed } \\
\text { yield per bunch } \\
\text { (number) }\end{array}$ & $\begin{array}{c}\text { Incremental seed } \\
\text { yield per bunch } \\
(\%)\end{array}$ & $\begin{array}{l}\text { Potential } \\
\text { incremental } \\
\text { revenue after } \\
\text { germination* } \\
\text { (USD) }\end{array}$ & $\begin{array}{l}\text { Reduction in } \\
\text { number of } \\
\text { inflorescences } \\
\text { required for } \\
1 \text { million seeds }\end{array}$ \\
\hline Polyester over HDPE & 128.71 & 13.28 & 96.53 & 161 \\
\hline Polyester over canvas & 65.17 & 6.31 & 48.88 & 77 \\
\hline Canvas over HDPE & 63.54 & 6.55 & 47.65 & 85 \\
\hline
\end{tabular}

Note: *Assuming 75\% germination rate. HDPE - high density polyethylene. 
Potential Impact of seed on incremental revenue

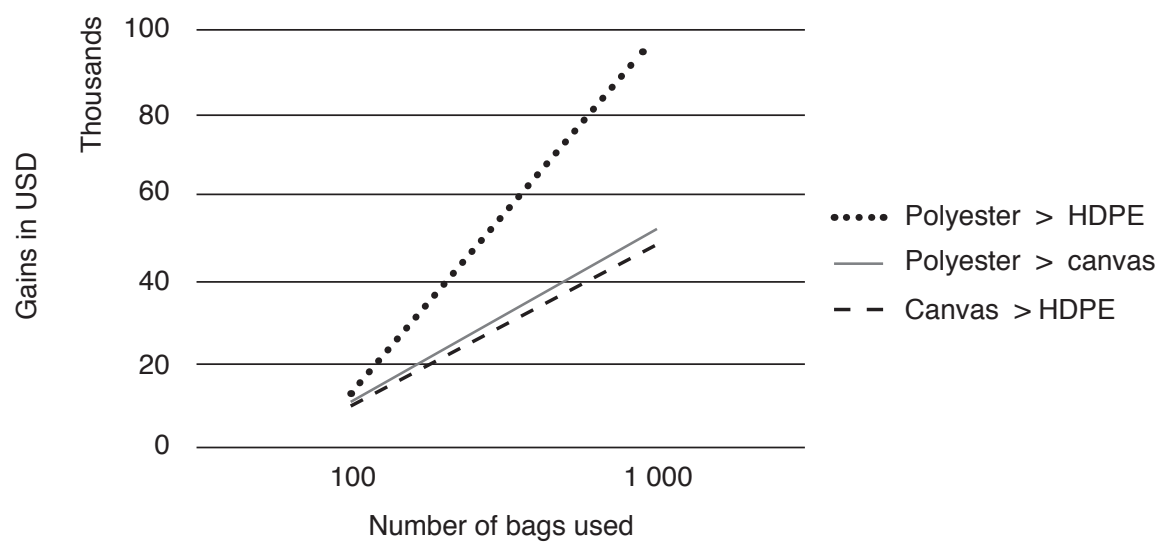

Note: HDPE - high density polyethylene.

Figure 3. Potential revenue gains from greater seed yield, comparing different pollination bag types (USD).

preserve the integrity of seed produced. Different types of bags have differential performance in this respect. For instance, McAdam et al. (1987) tested the efficiency of pollination bags made up of three grades of polyester and other three kinds of paper bags in Lolium perenne, where leaf phosphoglucose isomerase (PGI) isozymes were used to identify the parentage of the progeny. Some similar studies have been conducted in switchgrass by Vogel et al. (2014) using micro-mesh fabrics and Adhikari et al. (2015) using molecular techniques to detect the effect of foreign pollen on the progeny of bagged inflorescence.

Actual seed set in the bags is highly influenced by environmental conditions within the bag (Foster, 1968 in rye grass and Gitz et al., 2015 in sorghum) and on the amount of pollen used by workers (Harun and Noor, 2002). Gitz et al. (2015) found differences in micro-environmental conditions within spunbond poltethylene and brown paper bags in sorghum. They found that temperatures within polyethylene bags were lower than paper bags because of air permeability. Humidity was lower in soft polyethylene bags than hard polyethylene and paper bags that resulted in molds especially in the recently irrigated plants. Hayes and Virk (2016) found in Miscanthus that polyester bags exhibited a narrower range of temperature and humidity than those shown by the Wholesale Orchard and Glassine bags which could impact the success of crossing and seed set rate. The polyester bags made from non-woven fabrics allow air-permeability and moisture absorption for micro-environmental adjustments conducive for better seed set and development.

Our studies also demonstrate that the choice of pollination bag material does have a significant impact on seed set and seed yields in a commercial seed production setting. Of the canvas, HDPE and polyester material, we detected a significantly higher seed yield by polyester than HDPE and canvas bags, canvas showed higher seed yield than HDPE. Possible explanations for this incorporate several factors - the field performance results suggest some of them. In the usability studies, the HDPE and canvas bags were observed to sag onto the inflorescence when wet. This may damage the flowers, reducing the number capable of producing seeds. However, the canvas bags also sagged when wet to a greater extent than HDPE, yet seed set was higher for the canvas than HDPE bags.

Alternatively, the humidity levels inside the bags may affect the pollination rate, for instance the pollen may stick to a damp bag surface, affecting its dispersal around the inflorescence and limiting the pollination rate. A third possible explanation is that some combination of these factors is at play; for instance, increased humidity and sagging onto the bag may create an environment which encourages disease such as fungal infections, reducing seed set and increasing discards.

To shed light on this, tests were made on both HDPE and polyester to compare breathability using test method BS EN ISO 9237:1995 (ISO, 1995). This involves measuring air movement across a membrane at a given pressure difference between the two sides. At a pressure drop of $100 \mathrm{~Pa}$, polyester showed an air permeability of $110 \mathrm{~m} \mathrm{~m}^{2} \mathrm{~s}^{-1}$. The HDPE needed a pressure drop of $700 \mathrm{~Pa}$ to record air permeability of $1.051 \mathrm{~m}^{2} \mathrm{~s}^{-1}$. This much lower level of air permeability may be causing high humidity levels inside the bag.

Moisture build up was substantial in the HDPE bags, with $6 \%$ bags accumulating an average of 4 litres of water over the course of the observation period. This was syringed out and measured daily. In a normal seed production environment, the additional labour may not 
TABLE 13. SUMMARY OF RESULTS FOR VARIOUS PARAMETERS

\begin{tabular}{|c|c|c|c|}
\hline Characteristic & Canvas & HDPE & Polyester \\
\hline Intactness & Collapse & Collapse & Intact \\
\hline Presence of insects & Present & Absent & Absent \\
\hline Water retention & Slight & Water present & None \\
\hline Time taken for bagging & Longest & Shortest & Shortest \\
\hline Seed number per bag & Middle & Lowest & Highest \\
\hline Additional revenue (USD); & USD 47652 vs. HDPE & Lowest & USD 96530 vs. HDPE \\
\hline extra seeds from 1000 bags & & & USD 48878 vs. canvas \\
\hline
\end{tabular}

Note: HDPE - high density polyethylene.

TABLE 14. SUMMARY OF STATISTICAL SIGNIFICANCE OF RESULTS

\begin{tabular}{llll}
\hline Parameter & HDPE vs. canvas & Polyester vs. HDPE & Polyester vs. canvas \\
\hline Intactness & ns & Polyester better ** & Polyester better ** \\
Water & HDPE inferior ** & Polyester better ** & Polyester better ** \\
Time to apply & HDPE better ** & ns & Polyester better ** \\
Seed count & Canvas better** & Polyester better ** & \\
average/bunch & & & \\
\hline
\end{tabular}

Note: $*{ }^{* *}, * * *$ Significant at $5 \%, 1 \%$ and $0.01 \%$ probability level respectively. ns - not significant.

HDPE - high density polyethylene.

be available to inspect and remove water accumulation - moreover the increased risk of contamination by unintended pollen as a result of extra holes being made in the bag may not be acceptable. The results for this type of bag may not, therefore, be representative of the actual field performance. If the accumulated water is allowed to stand, the seed yields might be expected to be rather lower than those observed in this study.

The canvas bags, for reasons stated earlier, may also have additional costs that are not reflected here. The field performance work suggested that weevils and other insects were sometimes identified inside the canvas bags. Since insects are an important pollinator for E. guineensis Jacq. palms, this is typically taken as evidence of contamination, and most seed producers would discard bunch rather than risk the genetic integrity of the seeds they sell. Canvas bags were also observed to take significantly longer to affix than the HDPE or polyester bags, increasing field labour, and were more prone to be stolen.

A full analysis of the costs was not within the scope of this study. For instance, labour costs, processing and administration costs were not compared, neither were the costs of the bags themselves which can vary substantially due to the materials used and origin of the products. Nonetheless, there are some indications that certain operating costs would be higher than polyester, on account of the characteristics of the materials in the field.

Extending these results to other seed production environments should be done with care. For instance, other factors affect the number of seeds per bunch. A seed garden with a younger average age of their E. guineensis Jacq. palms, or a seed garden producing E. oleifera (Kunth) Cortés x E. guineensis Jacq. hybrids may be expected to see fewer seeds per bunch on average. This may therefore potentially affect the absolute level of difference observed between bag types, although the relative difference is much less likely to vary as this is highly likely to be a consequence of the fundamental properties of the different material types.

\section{CONCLUSION}

This investigation has clearly established that of the three pollination bag types (canvas, HDPE and polyester), the most ambient micro-environment conducive for healthy seed production was created by polyester pollination bags (Table 13) that was measured by intactness, presence of insects, impact of water and average time taken for bagging. Bunches isolated with polyester bags produced higher number of seeds than the other two type of bags resulting in more profitable seed production. An overall summary of results given in Table 14 demonstrates the advantage of polyester pollination bags for oil palm seed production.

\section{ACKNOWLEDGEMENT}

We are grateful to NBPOL Management for allowing the use of its asset in Papua New Guinea at Dami OPRS for this study. 


\section{REFERENCES}

ADHIKARI, L; ANDERSON, M P; KLATT, A and WU, Y (2015). Testing the efficacy of a polyester bagging method for selfing switchgrass. BioEnergy Res., 8: 380-387.

BALL, S T; CAMPBELL, G S and KONZAK, C F (1992). Pollination bags affect wheat spike temperature. Crop Sci., 32: 1155-1159.

BASRI, M W; HALIMA, A H and HITAM, A H (1983). Current status of Elaeidobius kamerunicus Faust and its effects on the oil palm industry in Malaysia. PORIM Occasional Paper No. 6: 39.

BASRI, M W and NORMAN, K (2007). Role and effectiveness of Elaeidobius kamerunicus, Thrips hawaiiensis and Pyroderces sp. pollination of mature oil palm in Peninsular Malaysia. Elaeis, 9: 1-16.

BRIDGWATER, F E; BRAMLETTZ, D L; BYRAM, T D and LOWE, W J (1998). Controlled mass pollination in loblolly pine to increase genetic gains. Forestry Chronicle, 74: 185-189.

CIEC_PROMOTING_SCIENCE (2015). Polymers poly(ethene) (polyethylene). University of York, York, UK. http://www.essentialchemicalindustry. org/polymers/polyethene.html, accessed on 14 August 2015.

CORLEY, R H V and TINKER, P B H (2008). The Oil Palm. $4^{\text {th }}$ edition. Wiley-Blackwell. 592 pp.

DEL Río, C and CABALLERO, J M (1999). A new bag for olive pollination studies. Acta Horticulturae, 474: 233-236.

FOSTER, C A (1968). Ryegrass hybridization: the effects of artificial isolation materials on seed yield and floral environment. Euphytica, 17: 102-109.

GITZ, D C; BAKER, J T; XIN, Z; BURKE, J J and LASCANO, RJ (2015). The microenvironment within and pollen transmission through polyethylene sorghum pollination bags. American J. Plant Sci., 6: 265-274.

HARRIES, C H (1972). Isolation bags fitted with with screw caps to simplify cross pollination. Euphytica, 2: 117-120.

HAYES, C and VIRK, D S (2016). Assessing the relative efficacy of polyester pollination bags and crossing tents, and isolation chambers for seed harvest in Miscanthus crosses. Int. J. Plant Breed. Genet., 10: 79-90.
HARUN, M H and NOOR, M R M (2002). Fruit set and oil palm bunch components. J. Oil Palm Res. Vol. 14: 24-33.

HODGES, E R S (2003). The Guild Handbook of Scientific Illustration. Wiley.

IBRAHIM, IF; BALASUNDRAM, S K; ABDULLAH, N A P; ALIAS, M S and MARDAN, M (2012). Morphological characterization of pollen collected by Apis dorsata from a tropical rain forest. International J. Botany, 8: 96-106.

ISO (1995). Textiles -- determination of the permeability of fabrics to air [online]. ISO. http: / / www.iso.org / iso / catalogue_detail. htm?csnumber=16869, accessed on 14 August 2015.

MCADAM, N J; SENIOR, J and HARWARD, M D (1987). Testing the efficiency of pollination bag materials. Plant Breed., 98:178-180.

MCGRANAHAN, G H; VOYIATZIS, D G; CATLIN, P B and POLITO, V S I (1994). High pollen loads can cause pistillate flower abscission in walnut. J. American Soc. Horti. Sci., 119: 505-509.

MENENDEZ, T and PRIOR, R (1982). Entomology section. Annual Report, 1981. Kimbe: Papua New Guinea Oil Palm Research Association.

NEAL, P R and ANDERSON, G J (2004). Does the 'old bag' make a good 'wind bag'? Comparison of four fabrics commonly used as exclusion bags in studies of pollination and reproductive biology. Ann. of Bot., 93: 603-607.

NEL, A; VAN STADEN, J and BORNMAN, C $\mathrm{H}$ (2003). Micro-fibre pollination bags and high viability Pinus patula pollen enhance cone survival and seed set during controlled pollination. South African J. Botany, 69: 469-475.

PICKERING, R A (1982). The effect of pollination bag type on seed quality and size in Hordeum: inter- and intraspecific hybridization. Euphytica, 31:439-449.

SMITH, D C and MEHLENBACHER, S A (1994). Use of Tyvek housewrap for pollination bags in breeding hazelnut (Corylus avellana L.). Hortscience, 29: 918.

SNEDECOR, G W and COCHRAN, W G (1974). Statistical Methods. $6^{\text {th }}$ Edition. Iowa State University Press, USA.

VOGEL, K P; SARATH, G and MITCHEL, R B (2014). Micro-mesh fabric pollination bags for switchgrass. Crop Sci., 54: 1621-1623. 
WINDHAM, G L and WILLIAMS, W P (2007). Effect of ear bagging systems on Aspergillus flavus kernel infection and aflatoxin contaminatuion of corn hybrids grown in the field. Phytoparasitica, 35: 277281.
WYATT, R; BROYLES, S B and DERDA, G S (1992). Environmental influences on nectar production in milkweeds (Asclepias syriaca and A. exaltata). American J. Botany, 79: 636-642. 